Authors' pre-print version

To be published as: Vermeersch P.W., Heylighen A., Involving Blind User/Experts in Architectural Design: Conception and Use of More-Than-Visual Design Artefacts, CoDesign

Please refer to the final published version. 


\title{
Involving Blind User/Experts in Architectural Design: Conception and Use of More-Than-Visual Design Artefacts
}

\author{
Peter-Willem Vermeersch ${ }^{\mathrm{a}, \mathrm{b} *}$ and Ann Heylighen ${ }^{\mathrm{a}}$ \\ ${ }^{a}$ KU Leuven, Department of Architecture, Research [x]Design, Leuven, Belgium; ${ }^{b}$ (Full) \\ Scale Architecten, Leuven, Belgium \\ *Corresponding author: \\ Peter-Willem Vermeersch
}

Kasteelpark Arenberg 1 bus 2431

3001 Leuven

+3216321334

$+3216321391$

peterwillem.vermeersch@kuleuven.be

http://orcid.org/0000-0002-3809-444X

\author{
Ann Heylighen \\ https://orcid.org/0000-0001-6811-3464
}

Architectural design as collaborative practice relies on using representational artefacts. However, these artefacts and their use are prone to a visual bias, which may pose problems in co-designing with vision impaired people. The research question addressed in this article is therefore: how can we develop representational artefacts to support a discussion between architects and blind people, and how do these artefacts mediate the discussion? We performed a three-month focussed ethnography using participant observation in an architectural design firm involved in a competition design. In agreement with the architects, we introduced two blind persons as user/expert at distinct moments. Together, we developed and tested visuo-haptic design representations. We analyse how these representations were conceived and used. We first discuss how the representations perceptually and cognitively support verbal and gestural communication. Secondly, we explain why, after having analysed their use in a design meeting, we move from the term 'tactile model' to 'visuo-haptic model'. 
And thirdly, we discuss how the ownership of the models shifts and how that relates to the ownership of the design. To conclude, visuo-haptic design representations can support aspects of co-design with blind people, but raise further questions for the role of representation in co-design in general.

Keywords: architecture; blindness; inclusive design; mediation; visuo-haptic models; user/experts

This work was supported by the European Research Council under the European Community's Seventh Framework Programme [Grant 201673]; and by the Research Fund KU Leuven [Grant No. C14/16/047].

No potential conflict of interest was reported by the authors.

Word count: 7518 


\title{
Involving Blind User/Experts in Architectural Design: Conception and Use of More-Than-Visual Design Artefacts
}

\author{
Architectural design as collaborative practice relies on using representational \\ artefacts. However, these artefacts and their use are prone to a visual bias, which \\ may pose problems in co-designing with vision impaired people. The research \\ question addressed in this article is therefore: how can we develop \\ representational artefacts to support a discussion between architects and blind \\ people, and how do these artefacts mediate the discussion? We performed a \\ three-month focussed ethnography using participant observation in an \\ architectural design firm involved in a competition design. In agreement with the \\ architects, we introduced two blind persons as user/expert at distinct moments. \\ Together, we developed and tested visuo-haptic design representations. We \\ analyse how these representations were conceived and used. We first discuss how \\ the representations perceptually and cognitively support verbal and gestural \\ communication. Secondly, we explain why, after having analysed their use in a \\ design meeting, we move from the term 'tactile model' to 'visuo-haptic model'. \\ And thirdly, we discuss how the ownership of the models shifts and how that \\ relates to the ownership of the design. To conclude, visuo-haptic design \\ representations can support aspects of co-design with blind people, but raise \\ further questions for the role of representation in co-design in general.
}

Keywords: architecture; blindness; inclusive design; mediation; visuo-haptic models; user/experts

\section{Introduction and state of the art}

Designing is understood as a collaborative enterprise (Bucciarelli 1988) where people interact through representational artefacts. These artefacts mediate processes of action, perception and cognition. They are technologies devised to help designers present, interpret and discuss design proposals. They are delegated certain actions through inscription (Latour 1993) and can invite or inhibit particular use (Verbeek 2005). They take part in cognitive processes - i.e., propagations of representational states, distributed over cerebral and material media (Hutchins \& Klausen 1996, Hutchins 2000). 
Furthermore, technological artefacts take part reducing and amplifying perception (Ihde 1993; Verbeek 2005). Thus follows that also architects' actions, cognition and perceptions are mediated by the tools they use to design. A well-known example of this mediation is the back-talk of a sketch (Schön 1983).

As artefacts mediate design by their presence and appearance, the design tools architects use arguably relate to the apparent visual bias in architecture (Pallasmaa 2005, Dischinger 2006). This bias has been observed in design practice, architectural journalism, critique and theory (Pallasmaa 2005). The input from the professional hinterland architects look for (Heylighen \& Neuckermans 2002) is largely visual in nature. Even when representational artefacts inherently can be interpreted in other ways than by vision alone (e.g., 3D models can be touched), as designers, architects tend to focus on the visual information they contain (Cross 1982). Still other media architects use (e.g., drawings, sketches, computer screens, printouts from CAD models) are mainly scripted for visual use.

The visual bias in architecture's production is particularly striking when one considers the spatial experience of vision impaired people. They benefit from nonvisual aspects in the built environment, which architects often overlook (Herssens \& Heylighen 2011). More in general, architects 'prioritize professional and technical knowledge over user or experiential perspectives, and very few disabled people are able to influence directly the design process' (Imrie 2000). They 'have limited knowledge of the building needs of disabled people and rarely engage with them' (ibid. 216-217). Ostroff (1997) therefore argues for involving users (in general, not just disabled users) in design as user/experts for their experiential knowledge on dealing with the built environment. For vision impaired people, however, the visual bias in architecture forms a barrier to their involvement. 
Luck et al. (2003) studied the involvement of, amongst others, vision impaired people in constructing a design brief. They concluded that tacit knowledge can be transferred between users and architects through descriptive narratives of other buildings users know, but that vocabulary to describe some architectural qualities is only basic. Our study therefore focuses on design artefacts to complement a basic common vocabulary.

If we want to co-design with vision impaired people, the design artefacts used need to be inclusive (Metatla et al. 2015). The research question addressed in this article is therefore: how can we develop representational artefacts to support a discussion between architects and blind user/experts, and how do these artefacts mediate the discussion? In Akrich's (1993) theoretical framework, technological objects' conception and eventual use are closely intertwined: how an object will be used and by whom are considered during its conception by means of use and user representations. Akrich describes innovators' rich definition of an object's use as also comprising the context of its use: both the environment the object will most likely be used in and the actors' cognitive, psycho-motor and social competencies. For her a project of innovation involves elaborating a scenario, constituted by a program of action; redistributing the program's realization amongst different actors; and representing the space where the action will take place. Hendriks et al. (2015, referring to Lee (2014)'s method stories) also advocate a focus on the making of co-design methods as much as on the outcome of their adoption.

This article reports on the conception and use of more-than-visual design artefacts in collaboration with two blind user/experts. We analyse the artefacts' intended and actual use and how they mediate the course of a design meeting. 


\section{Research approach and empirical background}

The study presented here fits within a larger research project, investigating the possibilities of involving blind user experience in architectural design. One track addresses the role of representational artefacts therein. For the larger project, an ethnography was performed in an architecture firm (two senior architects, two junior architects) participating in a competition design. A competition design is fixed in time and forces architects to explicitly communicate their design decisions to a jury (Lindekens 2006). The limited time, here three months, motivated the choice for a focussed ethnography (Knoblauch 2005), which compensates a shorter time in the field by thorough preparation, use of audiovisual recordings, and iterative data preparation and analysis. In consultation with the senior architects, two blind user/experts were introduced at distinct moments of the design process: a site visit, two workshops to develop representational artefacts, a collaborative design meeting, and a meeting in which the user/experts were presented the final design. ${ }^{1}$ Afterwards separate follow-up interviews were conducted with the architects and user/experts.

The aim was to provide the user/experts a sufficient understanding of the design (its spatial configurations) to enable them giving feedback on how they would experience and use the building, and expressing how they would change the design to accommodate their needs.

The following people were involved:

\footnotetext{
${ }^{1}$ Originally a broader involvement of the user/experts was foreseen, yet the architects experienced the user/experts' opinions as critiques for which they felt they had insufficient arguments to deal with in this early stage of the design. This limited the moments in which the architects participated in collaborative settings.
} 
- two blind people participated as user/experts (UE1, UE2) during the site visit and workshops; UE2 also participated in the design meeting;

- one researcher with a background in architecture (RA, author 1) participated in the design process as junior architect; another researcher $(\mathrm{R})$ with a background in sociology/anthropology took the role of observer recording the meetings on video;

- $\quad$ one senior architect (A) participated in the design meeting, not in the workshops.

\section{[INSERT TABLE 1]}

The architecture firm was chosen for its experience with competition designs. The blind user/experts were chosen for their interest in the built environment and availability during the period of the competition. They are used to paying attention to their surroundings and verbally explaining that to others. UE2 was involved in a previous research project, and has an interest and fluency in expressing her experience in the built environment. She suggested to involve UE1 as well. Both started with a personal interest in the involvement. We emphasized that we wanted them to express their own experiences rather than represent blind people. The building to be designed was a town hall (with public functions and offices). They did not live in this town, so had no immediate stake in the design, but both were familiar with the functions of a town hall, and thus could contribute from prior experiences.

RA joined the team as architect involved in the competition design (apart from a two week pilot, he had no prior involvement in the firm). This provided cultural insider knowledge and a position to insert an experimental element in ethnographic research on design practice, c.q., involving user/experts. 
Our analysis focused on those moments when representational artefacts were jointly developed and used, i.e., the workshops, the collaborative design meeting, and the follow-up presentation with the user/experts. The senior architects did not invite the user/experts for the official competition presentation, to not burden the jury. Therefor the researchers gave a follow-up presentation.

A setup with two cameras allowed capturing both the meetings' general context (where people are sitting, how they are positioning the design representations) and the minute interactions with the representations (what gestures are made around them, how they are altered, e.g. sketched on or folded) (Jordan and Henderson 1995). Collecting data through video allowed RA to combine the roles of participant designer and researcher (analysing the data concerning the design process). Distributing the roles over two researchers avoided having to disrupt the act of designing, while the minute interactions are captured for analysis afterwards. As video captures talk, gestures, the material setting and objects involved in social interaction, it provides 'a resource with which to analyse 'situated' action; as it emerges within its ordinary ecologies' (Heath \& Hindmarsh 2002). It allows analysing how representational artefacts are produced and used during design, what is said about and with them, and how they take part in cognitive activities in so far as they concern those distributed to objects or the environment. In addition, all representations (sketches, drawings, models) made during the workshops and design meeting were archived for later analysis. For each recording (audio, video, document) the date, content and date(s) of adaptation or re-use were kept in a logbook.

A semi-structured interview guide with open ended questions was used to focus the interviews, but leave room for the interviewees to discuss issues important to them. 
To prepare the data for further analysis, drawings were digitally scanned and models were photographed from different angles for easy viewing and note taking. Interviews were audio-recorded and transcribed word-for-word. Of all videos, content logs were made that divide the sessions in vignettes, describing for each what was said and done, to decide our focus. The videos of the workshop and design meeting were also transcribed word-for-word, and eventful vignettes were viewed repeatedly. Thus, although involved as designer, RA could find in the data what was said about the design representations by the participants, including himself. He could also identify who performed specific actions with the representations.

The processed data were analysed thematically starting from Akrich's (1993) concepts of inscribed psycho-motor, social and cognitive competencies. This method 'identifies, analyses and reports patterns. It minimally organises and describes your data set in (rich) detail. However, it also often goes further than this, and interprets various aspects of the research topic' (Braun \& Clarke 2006). Relevant transcripts and content logs were coded. Coding starts from the researchers' background knowledge building on Akrich's concepts, but allows adding codes particular to the data set. It is a structured approach that departs from a theoretical basis, and provides flexibility to interpret the data in their proper context. The coded chunks formed the basis to develop further themes which form the structure for the reporting below.

The study was limited to the involvement of one architecture firm, following one design in the very early stages. Only two blind people were involved, both in conceiving the models and testing their own models. This makes that the study reports on and analyses one very specific case. We claim no generalizable conclusions. For instance developing more generally applicable guidelines towards practitioners will 
need further research, combining insights from this study with those of other situations where blind people were involved in designing.

\section{Conceiving and testing more-than-visual design artefacts}

Our analysis of the design artefacts' conception and use is structured along the three types of competency Akrich advanced, although in reality they overlap. For each competency type, we further focus on aspects that received most attention during the workshops.

\subsection{User representation and knowledge}

In the conception of the scale models, the program of action was for the user/experts to understand the design proposal and be able to criticize and manipulate it by redistributing this understanding over the persons and artefacts involved. All this would take place in an architecture firm's office, with the participants seated around a table with the models in between. The first workshop focused on discussing model making techniques and materials. In the second workshop, the scale models were produced by RA and jointly tested in multiple iterations.

The knowledge to develop the models came from four sources. First, the researchers had gained important insights from observing two blind architects, and interviewing them about methods and tools they use to (re)present designs (Vermeersch \& Heylighen 2010). Secondly, insights had been gained by analysing the building site and buildings present during and after the joint visit. Thirdly, the user/experts have knowledge of representations and environments through their education, daily activities and engagement with the built environment; knowledge they exchanged during the site visit, workshops and design meeting. Fourthly, RA has specific cultural knowledge of 
making and using models during design. In line with how architects use design representations for discussion, three scale models were devised that represent the site and the architects' design intentions.

\subsection{Inscribed psycho-motor competencies: perception through touch}

During the workshops, the first discussion point was how to gain an understanding of the design. UE1 described how she had experienced collaborating on the redesign of her own house ${ }^{2}$.

\section{[INSERT FIGURE 1]}

Having a representation she can perceive is important for UE1 to 'imagine' the design, c.q., gain a spatial understanding of objects, spaces and relative positions: a 'sense of height and depth'.

During meetings preceding the workshops, the architects frequently used an aerial photograph of the building site with the site borders drawn on it. This document served as underlay both for testing different volumetric configurations to accommodate the program in plan, and for making a three-dimensional model. The latter represented the buildings on the site by cardboard volumes, some fixed with glue, others reconfigurable. Arbitrary volumes each represented one floor of certain dimensions, which could be stacked and moved around on the base plate to test different site layouts. Based on UE1's account (Vignette 1), this model was used as a starting point in the workshop.

\footnotetext{
${ }^{2}$ All quotes have been translated from Dutch to English by the authors, trying to convey the content of what was said
} 
While UE1 explored the model with her hands or the researchers guided her finger across the model, they verbally described to her what each volume represented. During the handling, however, this model quickly failed (Vignette 2). To allow moving the volumes around and testing different building configurations on the site, the volumes initially had not been fixed. By touching these volumes, UE1 displaced them and, since few other elements were discernible, quickly got lost in the model, not knowing anymore how different volumes related.

\section{[INSERT FIGURE 2]}

The model needed to be more robust to touch and contain more discernible shapes and elements of the site. Making more elements recognizable through touch would allow UE1 to orient herself correctly and faster.

\section{[INSERT FIGURE 3]}

As Vignette 3 illustrates, UE1 could situate parts of the site in relation to each other because she remembered from the site visit, but was unable to situate her experiences in relation to the model since it contained too little information that is legible through touch.

The adaptation resulted in a first model (Figure 4) on the scale of the source model (1:1000), providing an 'overview' of the building site, its immediate surroundings and the different building volumes on site (both existing and newly designed).

\section{[INSERT FIGURE 4]}

Structuring lines (representing e.g., site or street borders) were raised or dented. The 
volumes used were in themselves haptically ${ }^{3}$ discernible as three-dimensional objects. Also differences in material texture could be perceived tactilely and thus used to provide information. The volumes were fixed with semi-adhesive tape to remain reconfigurable. This was important to RA for the model to serve as design representation.

In the discussion about which elements of the site and design (not) to represent, another question arose: is this the right scale to present this or that design aspect? UE1 explained what she considers a balance between detailing and orientation within the model:

UE1:'The bigger, the more difficult. I prefer smaller and less detailed and closer together, then I can easily orientate through touch.' ......'If you start on how the building looks, then you need larger, if you want to show windows, you have to make it in pieces.'

UE1: 'You need orientation points, but it can't be overly detailed.'

As UE1 could not discern the different elements of the model anymore, two extra models were created that work together with the first to represent the design (Figure 56). The models are intentionally limited in size to support haptic exploration and overview (Vermeersch \& Heylighen 2010). Moreover, they seek a trade-off between sufficient information, sufficient overview, and the size of the hands. The choice of the scales was thus informed by the intentions to inscribe the psycho-motor competence of perceiving an object through touch and the cognitive competence of handling a certain

\footnotetext{
${ }^{3}$ Haptic perception combines both tactile and kinaesthetic perception (Loomis \& Lederman 1986). The sense of touch comprises two distinct senses: the cutaneous sense provides information through receptors in the skin, the kinaesthetic sense informs about dynamic and static body posture by the relative positioning of head, torso and limbs (ibid.).
} 
amount of information. At the same time, the scales chosen are familiar to architects, who would be using the models too.

\section{[INSERT FIGURE 5]}

While the first model offered an overview of the site, it was too small to provide details about the interior space and plan layout. Therefore a second model (Figure 5), on a scale of 1:500, limited the 'view' to the site and buildings on it. Like in the first model, the site was an extra cardboard layer and streets were dented lines in the base plate. As this model was intended to inform about the interior spatial organisation, buildings were represented by plans instead of volumes. Thin cardboard layers were piled up to create clear edges defining elements and spaces in the plan. The plans were still quite abstract, expressing the zoning (circulation, public desks, landscape office) rather than simulating every wall, door and window.

\section{[INSERT FIGURE 6]}

The third model (Figure 6) on a scale of 1:200 also focused on the interior, but provided more spatial detail than the second and was limited to one building wing. Its key perceptual feature was the possibility to go inside with one's hands. It was intended to offer a better understanding of the space and the organization of the main vertical circulation in the entrance wing, The model was largely made out of grey cardboard while pieces of paper with a rougher texture indicated circulation zones. To select the different textures the researchers discussed with the user/experts two options: a symbolic approach with a legend of materials and what they represent; or an iconic approach linking materials more 'intuitively' with what they represent, be it a material, atmosphere or function. 


\section{[INSERT FIGURE 7] ${ }^{4}$}

UE1 explained that a model which can be interpreted intuitively allows a more independent exploration than having to memorise a legend or key first (Vignette 4).

\subsection{Inscribed social competencies: communicating design}

The need for a material representation at hand relates not only to the user/experts' individual perception, but also to their communication with the architects, as one of its goals is to support gaining a mutual understanding of the design. If the models were to function as shared material context, they should work for both architects and user/experts. Therefore, the researchers started from representations that are traditionally used in architecture, and seemed promising in terms of haptic perception. As a result, both architects and user/experts could interpret the models, each in their own manner. This seemed a promising way of communicating the design, further intentions, and critiques. As illustration, we present a vignette from the second workshop. At this point, the user/experts are aware of the different kinds of architectural scales and UE2 is exploring model 1 (Figure 4) for the first time:

\section{[INSERT FIGURE 8]}

The models allowed UE2 to relate the different places and routes on the site. Somewhat later, UE1 also explored this model for the first time, after having heard the conversation between UE2 and RA:

\footnotetext{
${ }^{4}$ Translation: the original expression 'mijn plan trekken' asserts a positive attitude to being able to explore without help
} 


\section{[INSERT FIGURE 9]}

The model offered a material context to discuss spatial distributions. UE1 could even build on others' conversation by relating the verbal part of an explanation she was listening to with the model she was touching at her own leisure. Other spatial qualities discussed include proportions and dimensions; e.g., UE1 related $1 \mathrm{~cm}$ she felt in the model to $10 \mathrm{~m}$ in reality and, when touching the side of one building, qualified it as 'fairly wide'. Spatial relations and how they are perceived are aspects that need to be discussed in architectural design, which the models allow to.

During the workshops both parties gained a better understanding of each other's practices and concerns regarding the built environment and its design. For instance, different standpoints were exchanged about material use in scale models. RA explained that in a model he usually represents water by using a plastic sheet mimicking reflective qualities. UE2 replied that, based on her experience of water as waves in motion, a sheet of ribbed cardboard, which was lying on the table, would be more understandable for her. Discussions like this ranged from describing different use scenarios over sharing previous experiences with the 'other' to explaining design tools' use in architectural practice.

\subsection{Inscribed cognitive competencies: memory and reinterpretation}

Drawing from his experience as architect, RA proposed for the models to remain adaptable without forgetting the user/experts' need for sturdiness (see Vignette 2). Based on blind architects' design methods (Vermeersch \& Heylighen 2010), the researchers suggested wax, clay or modelling putty, yet the user/experts disliked touching these materials. Eventually, cardboard was combined with semi-adhesive tape. 
In order to allow cyclic practices of reinterpretation, to iteratively test multiple configurations, the models needed to be easily adaptable. For instance, the first model allowed testing different building configurations and heights by temporarily fixing volumes, evaluating the result, and proposing alternatives, while being sturdy enough to be touched. In a medium perceivable through touch, being able to (temporarily) fix the spatial configurations seems crucial (Vignette 1).

Unlike architects' common practice of spreading out several plans to look at in parallel, the second model stacked plans on top of each other. This was expected to facilitate relating and orienting two plans to each other. Throughout the stacked plans, the position of, say, the vertical circulation that connects different floors, and therefore recurs at each floor, remained the same. Remembering one's body posture when feeling a staircase on the ground-floor plan could thus help to find that staircase back on the first-floor plan, providing a known starting point for further haptic exploration.

\section{Using more-than-visual design artefacts in a design meeting}

The models developed in collaboration with the user/experts were used in a design meeting between one senior architect (A1), the researchers (RA and R) and one user/expert (UE2). In the following, we refer to A1 and RA jointly as 'architects'. We further describe how, during this meeting, the models mediated processes of perception, cognition and action in social and cognitive interactions.

\subsection{Providing a basis for social interactions}

In the beginning of the meeting, the architects and user/expert worked out a way to gain a common understanding of the design by talk, touch and gesture (Vignette 7). The models provided a means to discuss the design's spatial qualities. At first, UE2 used the models extensively to understand the architects' explanation of the design. The 
architects relied on talk to indicate the buildings on site and their relative positions. Meanwhile, UE2 followed their explanation in the model by moving her hands over and between buildings. Or the architects took her finger and they moved hands together.

\section{[INSERT FIGURE 10]}

To gain a spatial understanding, UE2 relied on the architect's narrative talk, her own exploration by hand and the A1's hand guiding. The architects used talk to identify elements, but took her hands to explain their relative positions. Similarly, UE2 followed the architects' narrative, suggesting that she used the model for the same reason: grasping spatial configurations of named elements.

Later in the meeting (Vignette 8), the situation inverted: UE2 explored the model in her own way, while the architects visually followed her hand movements and adapted their conversation accordingly.

\section{[INSERT FIGURE 11]}

UE2 used her hands to distinguish the relative sizes of building parts: she even explicitly compared distances between building parts as distances between her index fingers (Vignette 8). She combined this haptic spatial information with asking the architects for the lengths in meters to assess the (walking) distances: 'long'.

Meanwhile, the architects followed her hand movements visually, and interpreted the haptic explorative gestures also as indexical gestures combined with her indexical utterances like 'this' and 'that'. When preparing for a question, she explored the models to obtain the necessary information. But the actions for doing so were also seen by the architects. They knew what part of the design was under investigation and when UE2 formulated her query, they were already informed about the context or element under question. 
The conversation's indexicality coincided in part with UE2's manual explorations of the models. In Vignette 7, A1 changed his indexical gestures to coproduced gestures. He was the main instigator of the hand movements, but UE2 could follow or resist because the visual practice had become also a haptic practice. The models' presence and position in haptic proximity to UE2 also figured in how the architects negotiated the progress of the narrative.

\section{[INSERT FIGURE 12]}

In order to use the models, UE2 needed to have them in very close range. Therefore the architects had to negotiate control over the models with her, e.g., switching between the different ones in order to develop a narrative. RA wanted to move the narrative forward, but hesitated to move the models around, giving UE2 room to first explore the model by herself.

We observed here a particular negotiation of control over the meeting's narrative, but important is also what we did not observe happening, namely UE2 engaging with the design's concepts or contents. She did not make any propositions to alter the design. In a follow-up interview, UE1 (speaking for both) explained: 'The design was already there, and "what do you think?", and "how can we adapt thát?", but their design was already there.' During the second follow-up interview, she suggested that her reluctance to alter anything to the design, or make suggestions to improve it, had to do with the scale models: they gave the impression that the design itself was already fixed. She could criticize it in its own right, as presented in the models, but despite the efforts to make the models adaptable, she preferred to leave changing them, and thus the design, to the architects. 


\subsection{Building an understanding of the spatial configuration}

For some topics discussed during the meeting, the models provided an efficient means to guide the narrative, clarify questions, point out specific elements or refresh one's memory. These topics include the building program, concepts of plan layout (e.g., zoning), building phases, daylighting, but also how to move through the building, orient oneself or use it in different scenarios. All these topics seemed to benefit from a thorough understanding of the design's spatial configuration, its dimensions, proportions and the positions of the different elements vis-à-vis the whole and each other. More in general, the models seemed to help the discussion in terms of actual spatial configuration, but also the guiding concepts architects use to organize the space in such a way, and the consequences of this specific spatial configuration for wayfinding and building use.

At the point where UE2 started to question the design (e.g., Vignette 8), we observed in her active engagement again a support of spatial cognition in calculating distances. Her actions were mediated (partly) through the model as she brought the discussion to different design elements' dimensions. By enabling her to explore the design's spatial configuration, the model mediated her participation in the design meeting. She was no longer following, but measuring, pointing out distances, judging them to be 'long' -actively engaging in the discussion about lengths, proportions and configurations. The model took part in cognitive tasks of measuring and comparing volumes (Vignette 8). She went through the model haptically, taking with her fingers the length of one building volume to the others, relating the latter length to the distance known from the former lengths (verbally defined by the architects as ' $23 \mathrm{~m}$ '). The model's presence allowed UE2 to gain a second kind of understanding of the design's 
dimensions: haptically next to verbally, both in relation to prior experiences with walking distances.

\section{Discussion}

\subsection{How the models take up their role as representational artefacts}

The models show similar qualities as representational artefacts used in (architectural) design. For UE1 having (perceivable) representations is important for communicating explanations, imagining spatial configurations, and triangulating sources for imagination: talk and perceivable artefacts (Vignette 1). The models mediate how the discussion about the design is propagated by both architects and user/expert. Talk is flexible or vague, an important aspect of models as used in model-based-reasoning (Nersessian 1999, Glock 2009). Moreover, (temporarily) fixing a design in sketches benefits the design process by providing a medium for reinterpretation, communication and memory (Vanderlugt 2005). Spatial representations expanded with gestural representations thus complement the vagueness of a verbal model.

One function of external representations is 'to decrease the load on memory [...]. Since designing is always complex and a large number of memory items are involved, creating what may be called an 'external memory' that is instantly accessible any time helps reduce the cognitive load of trying to retrieve and maintain items from long- and short-term memory' (Goldschmidt 2014:439). Vignette 3 illustrates the importance of this external memory for the user/expert to re-establish how she is imagining the site. When the model failed to provide the information, her imagination also failed her, and the architects needed to correct her.

Literature on communicating design shows the importance of the 'talking' sketch (Ferguson 1992, Vanderlugt 2005) in providing a common shared visual context 
(e.g. Karsenty 1999). It makes communication more efficient by allowing for relative references: 'let's combine this with that' (Vanderlugt 2005: 106). It forms a basis for non-verbal conversational practices like gesturing around objects (Murphy 2005). In design meetings, gestures have two functions (Visser 2009): rendering spatial and motion-related qualities of entities; and organising social interaction. Both functions surface in the user/experts' exploratory gestures. Examples of the former include distinguishing elements, relative positions and dimensions, e.g. Vignette 8. The latter can be observed in the difference in UE2's agency between Vignette 7 where her exploratory gestures are steered by A1 (verbally or by taking the hand ${ }^{5}$ ), and Vignette 8 where her gestures steer the narrative of A1 (adapting his explanation to her hands' path through the model).

Another role of sketches in design relates to (re-)interpreting depicted design ideas (Goldschmidt 1991, Schön \& Wiggins 1992). Key to reasoning through models is the dynamic aspect of creative manipulations (Osbeck and Nersessian 2006, following Nersessian 1999). Model-based reasoning is based on the duality between fixing and manipulating: models are constructed to define a problem space, but allow drawing inferences from manipulation. Models are manipulated (physically, mentally, mathematically, gesturally) in the interaction between different persons and artefacts (Osbeck and Nersessian 2006). Manipulation can thus be as temporary as gesturing how to change a certain element in the design. Yet since models also serve to define a problem space, being able to fix some manipulations more permanently is helpful. A design move can be made verbally, by gesturing on the models, or by altering the model

${ }^{5}$ In an earlier analysis we termed this indexical practice 'co-produced gestures' (Vermeersch et al. 2011). 
itself. All these practices help the cyclic process of definition and reinterpretation (Goldschmidt 1991). In our study, the models provided a means to fix spatial configurations for further interpretation (Vignette 8), invited different kinds of gesturing (see above), and even provided a balance between temporary fixation and haptic use (Vignette 2; model 1).

In this study, it strikes us that the models did not contribute much to discussions on experiential qualities. Such discussions happened, just not with active involvement of the models (hence these discussion do not show up in the results). This relates to one of Luck's (2003) findings that 'insight into user experience of an environment, can be revealed through [verbal] discussion', thus diminishing the need for alternative means of communication.

\subsection{From' tactile' to 'visuo-haptic'}

Analysing two blind architects' design methods showed that they rely heavily on touch and representations made for haptic perception (Vermeersch \& Heylighen 2010). This informed the decision to make models on different scales (providing both overview and detail) while matching the size of the hands (see descriptions of models $1,2 \& 3$ ). Our earlier finding that the movement of the fingers is (sometimes) a proxy for the body 'walking through the model' was confirmed (ibid.): UE2 followed the circulation space from the building entrance towards the public desks (Vignette 8).

Although most studies use the term 'tactile model' or 'tactile map' (e.g., Perkins 2002), we label the models developed in this study as 'visuo-haptic'. The term 'tactile' does not sufficiently describe the richness of possibilities the sense of touch offers, which comprises both tactile and kinaesthetic senses (Loomis and Lederman 1986). When exploring the models, the user/experts relied on tactile perception to discern the different elements through differences in texture or raised edges. But their kinaesthetic 
sense informed them about these elements' position and shape through the distinct position of their fingers or hands relative to their body. Since this kinaesthetic aspect seems so important in the user/experts' spatial exploration of the models - witness their capability to quickly locate elements in them-it seems only fit to characterize the models as haptic, rather than tactile.

Furthermore, the initial intention was to produce a material spatial representation of a design in order to involve blind user/experts, who rely heavily on touch to perceive smaller objects. But quickly the models turned out to be very helpful in a visual way too. Besides through co-produced gestures, the architects interpreted both the models and how the user/expert handled them mainly visually. The models thus still have an inherent visual quality, both as an object and in the practices observed. Because in use the models contain many more possibilities to mediate perception than tactilely only, we call them 'visuo-haptic'.

\subsection{A shift in ownership of models, narrative but not design}

We observed a shift in agency during the design meeting, which can be explained by the models' visuo-haptic qualities. The division of a design's ownership between architect and client has been discussed before (Luck 2009, McDonnell 2009). We want to add a discussion of the ownership of the models, and the design's narrative.

The proximal nature of haptic exploration (versus the remote nature of vision) shifted the ownership of the models' use from the architects to the user/expert, as illustrated by the architects' hesitation (Vignette 9). The models enabled her to adopt an independent role in the meeting by exploring the design's spatial configuration on her own; they also enabled the architects to follow that same exploration and adapt to it. Rather than only follow the architects', UE2 could build her own narrative through the design, which the architects could follow visually (Vignettes 7 and 8). Her exploratory 
hand movements were interpreted by the architects as indexical cues. Besides communicating the design's spatial dimensions to the user/expert, the models turned out also to support the verbal communication between her and the architects. The change in the social environment (where the representational artefacts are closest to the person touching them) made thus also for a shift in ownership of the meeting's narrative.

Interestingly, the latter did not lead to a shift in ownership of the design itself. The models allowed making design moves, but our analysis suggests that this is insufficient for user/experts to make such moves themselves. The user/expert identified elements she could distinguish or the architects pointed out to her. When questioning the design, she also used these elements in framing the context of possible problems. However, she did not seem to feel confident enough to make any design move herself. In Schön's (1983) terms, she engaged in naming and framing different design elements, but did not make any design move, c.q., any proposition to alter (part of) the design. Although Visser (2009) suggests that designating gestures might be connected to design moves, we did not observe such connection.

The reluctance to alter the design, or make a proposition, seemed to be related to the scale models: they gave the impression that the design itself was already fixed. Another possible explanation (requiring further research) is the timing of the meeting between architects and user/expert. After the joint site visit/analysis, the first concepts were formed exclusively by the architects. Also in the workshops to make the models a similar reluctance to take control of the shaping of the models was observed. Of the suggested modelling materials, the user/experts preferred those they could not shape themselves. The workshops had to be adapted to an iterative process of making (by RA) and testing (by UE's) multiple instances of the models. 


\section{Conclusion}

Design practice is characterised by the use of representational artefacts, individually or collaboratively, amongst architects or with other stakeholders, together with talk or gestures. These artefacts are mostly scripted for visual use. To co-design with blind user/experts, representational artefacts were scripted for use through touch. After observing their use in a design meeting, we termed those artefacts visuo-haptic models. The models mediated the meeting as they allowed for haptic exploration by the blind user/experts, while enabling the architects to visually interpret their exploratory gestures as indexical practice. The models provided a means to establish a common ground concerning a design's spatial configuration. Once this configuration was well understood, the models provided a (temporarily) fixed physical representation to go back to when in doubt, point out elements under discussion, or clarify questions. This worked in both ways, allowing for practices like co-produced gestures.

Because of the models' presence, we observed a shift in the user/experts' agency from a verbal-gestural practice to an exploratory practice involving haptic representations. As a result, the ownership of the meeting's narrative shifted from the architects to the user/expert. However, such shift was not observed for the design itself as the setting (including the models' format) made her reluctant to make any design move. The models (and the design they represent) were experienced as fixed and the architects as responsible for making the design moves based on their critique.

In the design meeting different media (verbal, gestural, material) all contributed to communicating design intentions and critiques, often in combination. The need to adapt the representational artefacts architects use when involving blind user/experts, and the mediation of their involvement, also raises questions about co-designing with users in general: to what extent are architects' representations sufficiently adapted to involve 
users? Aspects of involvement may transcend perceptual impairment, as suggested by our observations concerning, e.g., the narrative's ownership, or the inhibition of design moves due to the apparent fixedness. Awaiting further research on these aspects, our study suggests that for something as complex as the spatial configuration of a building design, two- and three-dimensional visuo-haptic artefacts provide an important asset to design communication when involving blind user/experts.

\section{Acknowledgements}

We want to thank the user/experts and architects for their time and participation. We want to thank Greg Nijs for his contribution to the research. This work was supported by the European Research Council under the European Community's Seventh Framework Programme [Grant 201673]; and by the Research Fund KU Leuven [Grant No. C14/16/047].

\section{References}

Akrich, M. 1993. 'Les objets techniques et leurs utilisateurs.' Raisons pratiques, $\mathrm{n}^{\circ} 4$, 'Les objets dans l'action': 35-57.

Bucciarelli, L. L. 1988. 'An ethnographic perspective on engineering design.’ Design Studies 9(3): 159-168.

Cross, N. 1982. 'Designerly ways of knowing.' Design Studies 3(4): 221-227.

Dischinger, M. 2006. 'The non-careful sight.' In Blindness and the multi-sensorial city, edited by Devlieger, P. et al., 143-176. Antwerpen: Garant.

Glock, F. 2009. 'Aspects of language use in design conversation.' CoDesign 5(1): 5-19.

Goldschmidt, G. 1991. 'The dialectics of sketching.' Creativity research journal 4(2): 123-143.

Goldschmidt, G. 2014. 'Modeling the role of sketching in design idea generation.' In An antalogy of theories and models of design, edited by Chakrabarti, A., and Blessing, L. T. M., 433-450. London: Springer-Verlag.

Hendriks, N. et al. 2015. 'Codesign with people living with cognitive or sensory impairments.' CoDesign. 11(1): 70-82.

Herssens, J., and Heyglighen, A. 2011 'Challenging Architects to Include Haptics in Design: Sensory Paradox between Content and Representation.’ In Designing 
together - CAADfutures 2011, edited by Leclercq, P., et al., 685-700. Liège: Les Editions de l'Université de Liège.

Heylighen, A., and Neuckermans, H. 2002. 'Are architects natural case-based designers?' The Design Journal 5(2): 8-22.

Hutchins, E. 2000. 'Distributed cognition.' In International encyclopedia of the social and behavioral studies. 1-10. http://www.artmap-research.com/wpcontent/uploads/2009/11/Hutchins_DistributedCognition.pdf

Hutchins, E., and Klausen, T. 1996. 'Distributed cognition in an airline cockpit.' In Cognition and communication at work, edited by Engström, Y., and Middleton, D., 15-34. Cambridge: Cambridge University Press. http://hci.ucsd.edu/102a/readings/cockpit-cog.pdf

Ihde, D. 1993. Postphenomenology. Evanston, Illinois: Northwestern University Press. Imrie, R. 2000. 'Responding to the design needs of disabled people.' Journal of urban design. 5(2): 199-219.

Jordan, B., and Henderson, A. 1995. 'Interaction analysis.' The journal of the learning sciences. 4(1): 39-103.

Latour, B. 1993. We have never been modern. Cambridge, Massachusetts: Harvard University Press.

Lee, J. J. 2014. 'The true benefits of designing design methods.' Artifact. 3(2): 5-1.

Loomis, J. M., and Lederman, S. J. 1986. 'Tactual perception.' In Handbook of perception and human performance, vol. 2. edited by Boff, K. R., Kaufmann, J., and Thomas, J. P., 31.1-31.41. New York: John Wiley.

Luck, R. 2009. “'Does this compromise your design?”' CoDesign. 5(1): 21-34.

Luck, R. 2003. 'Dialogue in participatory design.' Design Studies. 24: 523-535

McDonnell, J. 2009. 'Collaborative negotiation in design.' CoDesign. 5(1): 35-50.

Metatla, O. et al. 2015. 'Designing with and for people living with visual impairments.' CoDesign, 11(1): 35-48.

Murphy, K. M. 2005. 'Collaborative imagining.' Semiotica. 2005(156): 113-145.

Nersessian N. J. 1999. 'Model-based reasoning in conceptual change.' In Model-based reasoning in scientific discovery. edited by Magnani, L. et al., 5-22. New York: Kluwer Academic/Plenum Publishers.

Osbeck, L. M., and Nersessian, N. J. 2006. 'The distribution of representation.' Journal for the theory of social behaviour. 36(2): 141-160. 
Ostroff, E. 1997. 'Mining our natural resources: The user as expert.' INNOVATION. 16(1).

Pallasmaa, J. 2005. The eyes of the skin - Architecture and the senses. United Kingdom: Wiley-Academy.

Perkins, C. 2002. 'Cartography: Progress in tactile mapping.' Progress in human geography. 26(4): 521-530.

Schön, D. A. 1983. The Reflective Practitioner. New York: Basic Books.

Van der Lugt, R. 2005. 'How sketching can affect the idea generation process in design group meetings.' Design Studies. 26(2): 101-122.

Verbeek, P. P. 2005. What things do. University Park, Pennsylvania: The Pennsylvania State University Press.

Vermeersch, P.W., and Heylighen, A. 2010. 'Scaling Haptics - Haptic Scaling: Studying scale and scaling in the haptic design process of two architects who lost their sight.' In Scale: Imagination, perception and practice in architecture, edited by Adler, G., et al., 127-135. Oxon Routledge

Vermeersch, P.W., et al. 2011. 'Mediating artifacts in architectural design: A non-visual exploration.' In Designing together - CAADfutures 2011, edited by Leclercq, P., et al., 721-734. Liège: Les Editions de 1'Université de Liège.

Visser, W. 2009. 'The function of gesture in an architectural design meeting.' In About: Designing. Analysing design meetings. Edited by McDonnel, J. et al., 269-284. London: Taylor \& Francis. 


\begin{tabular}{|c|c|c|c|c|c|c|c|c|c|}
\hline Events & UE1 & UE2 & A1 & A2 & $\begin{array}{c}\text { RA } \\
\text { (auth. 1) }\end{array}$ & R & $\begin{array}{c}\text { Junior } \\
\text { architects }\end{array}$ & $\begin{array}{c}\text { other } \\
\text { researcher } \\
\text { (auth. 2) }\end{array}$ \\
\hline Joint site visit & $1 \mathrm{~d}$ & $\mathrm{v}$ & $\mathrm{V}$ & $\mathrm{v}$ & $\mathrm{V}$ & $\mathrm{V}$ & $\mathrm{v}$ & & $\mathrm{V}$ \\
\hline $\begin{array}{c}\text { Design } \\
\text { activity }\end{array}$ & $4 \mathrm{w}$ & & & $\mathrm{v}$ & $\mathrm{v}$ & $\mathrm{v}$ & $\mathrm{v}$ & & \\
\hline $\begin{array}{c}\text { Workshop 1 } \\
\text { (techniques) }\end{array}$ & $1 \mathrm{~d}$ & $\mathrm{v}$ & & & & $\mathrm{v}$ & $\mathrm{v}$ & & \\
\hline $\begin{array}{c}\text { Workshop 2 } \\
\text { (development) }\end{array}$ & $1 \mathrm{~d}$ & $\mathrm{v}$ & $\mathrm{v}$ & & & $\mathrm{v}$ & $\mathrm{v}$ & & \\
\hline $\begin{array}{c}\text { Design } \\
\text { activity }\end{array}$ & $2 \mathrm{w}$ & & & $\mathrm{v}$ & $\mathrm{v}$ & $\mathrm{v}$ & $\mathrm{v}$ & & \\
\hline $\begin{array}{c}\text { Collaborative } \\
\text { meeting }\end{array}$ & $1 \mathrm{~d}$ & & $\mathrm{v}$ & $\mathrm{v}$ & & $\mathrm{v}$ & $\mathrm{v}$ & & \\
\hline $\begin{array}{c}\text { Design } \\
\text { activity }\end{array}$ & $4 \mathrm{w}$ & & & $\mathrm{v}$ & $\mathrm{v}$ & $\mathrm{v}$ & $\mathrm{v}$ & $\mathrm{v}$ & \\
\hline $\begin{array}{c}\text { Jury } \\
\text { presentation }\end{array}$ & $1 \mathrm{~d}$ & & & $\mathrm{v}$ & $\mathrm{v}$ & $\mathrm{v}$ & $\mathrm{v}$ & $\mathrm{v}$ & \\
\hline $\begin{array}{c}\text { Follow-up } \\
\text { presentation }\end{array}$ & $1 \mathrm{~d}$ & $\mathrm{v}$ & $\mathrm{v}$ & & & $\mathrm{v}$ & $\mathrm{v}$ & & $\mathrm{v}$ \\
\hline
\end{tabular}

Table 1. Overview of participants (architects, researchers, user/experts) and presence in the design process. Activities are chronological and an indication of the duration of each activity is given $(\mathrm{d}=$ days, $\mathrm{w}=$ weeks $)$.

Figure 1. Vignette 1

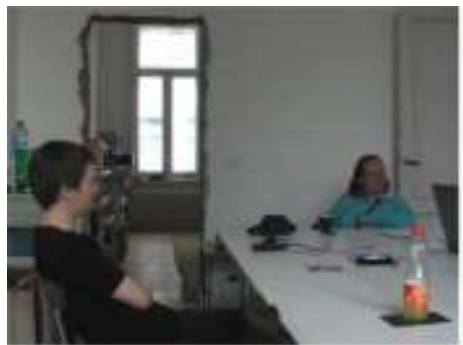

UEf: 'They [the architect] may explain everything, but you can only really know bow it boks when ir's finished."

RA: "That's so for everyore.'

UE1: 'But somcone looking at a plan can imagine it. for me that was not so.

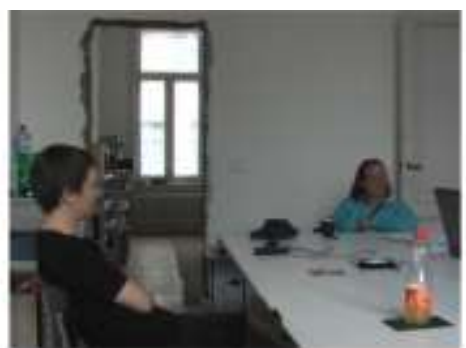

R: 'Is it because you can't follow the plan, of grasp its totality?

UE1: 'That's, bow sbouk1 I say, with a model I iruly could imsegine it. [..] Thas time when 1 had no model and the architoct drew it, 1 had not understood it although I knuw ny own house. [...] For the rear extensian, there was a model. and that was no sarprise, on plan it's difficult.

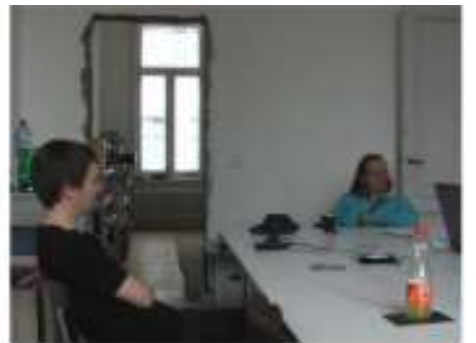

R: 'How so with the modkl?"

UEl: 'Because you can feel it, because you can imagine it as it would be. A plan, that's lines. you may trace it with your fingers but you stiil have no sense of height or depth. 
Figure 2. Vignette 2

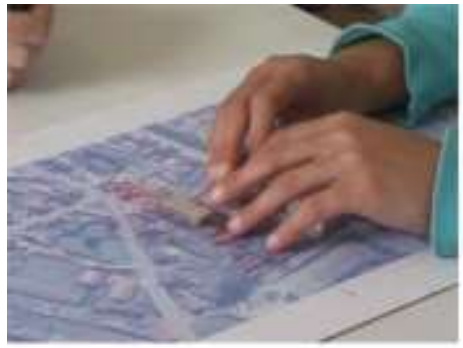

UEI's hands hover over the model, RA explains the U-shaped configuration of the design] RA: "where you create some kind of intimate inner spuce with park around. On the ground floor you can then make easy connections.'

Figure 3. Vignette 3

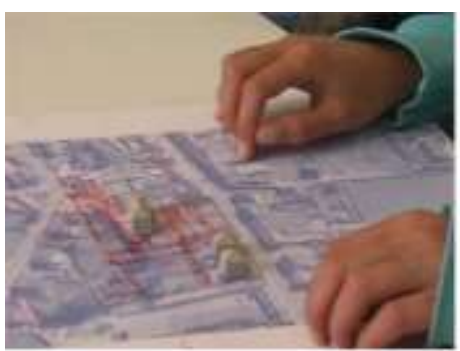

UEI: "That volume combs berc, in the midde of this grass field'

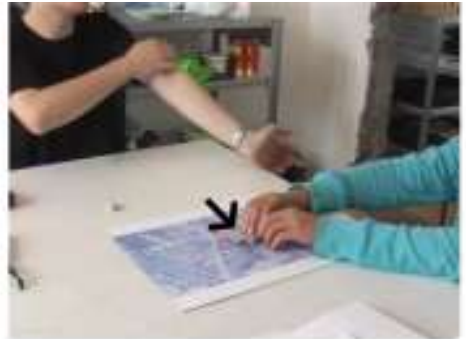

UEI: [moves her hand tawards the volumes and knocks them over] 'Oops, they've already toppled.'

[further discussion between UE] and RA about the open yround floor, UEI keeps her hands on the model]

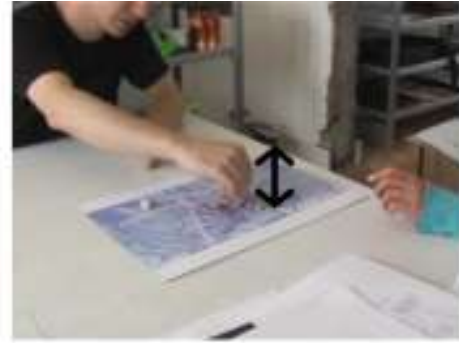

[RA repositivens the volumes on the model] RA: 'this model we made was meant to be looked at and not to be touched.

UEl: 'Tut I can still imagine it.'

RA: 'But if you start to touch, everything topples over.'

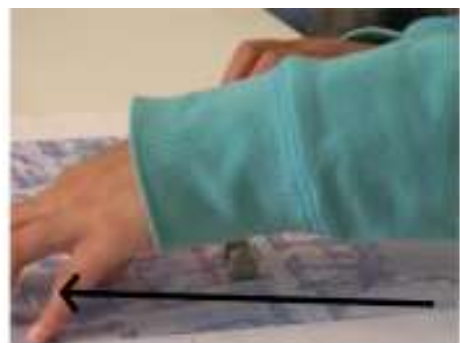

UE1: 'Ah that grass field, it was tack here?' [posinions her finger in a different pant of the model than the pant ste talks aboun]

R. 'you can't orientate yourself anymore'.

UEI: 'Yes I do, that grass field was here, behind those houses.' ['those bouses' are two villas on the site, and one of the few clemonts glued on the mode1]

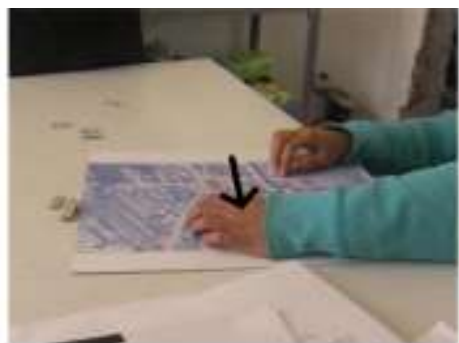

RA. 'Yes, but now you are in the oxtiphbouring school." [UE]'s hand is]

UE1: 'Yes but, yes'

R: 'Bus thar's noe a probkem per se.'

RA: 'We are also searching, apparesstly this modef is no good.

$R:$ 'The point is we want to make something that lets you know immediately where that grass fiekd

UE1: 'Td use a few other kinds of paper for the grass field.

Figure 4. Adaptable model representing the building site and building phases with different materials for existing and planned buildings
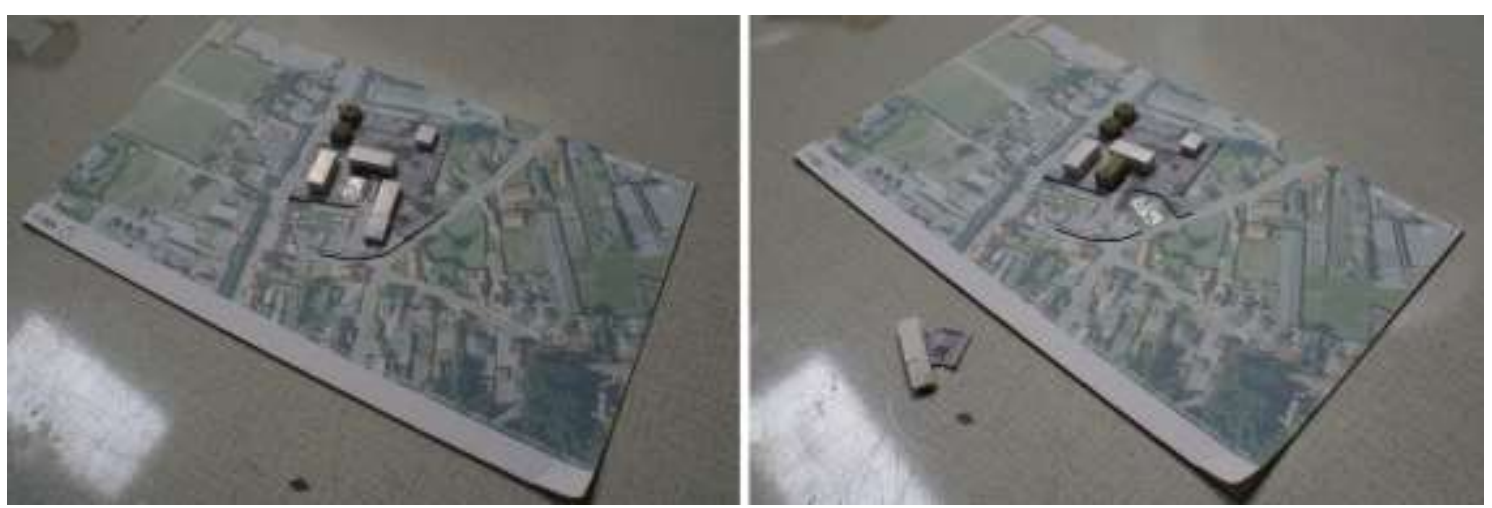
Figure 5. Adaptable model representing the layout of the building site and interior organization of the first floor
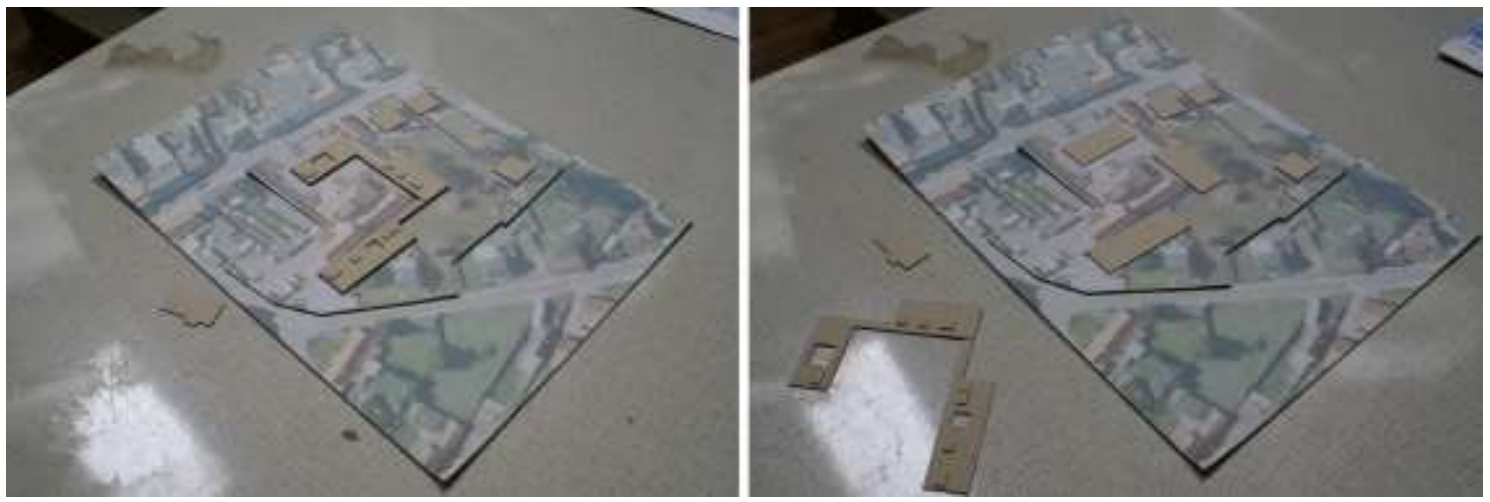

Figure 6. Adaptable model representing the interior circulation of one building wing, on a larger scale to allow going inside the model with the hands
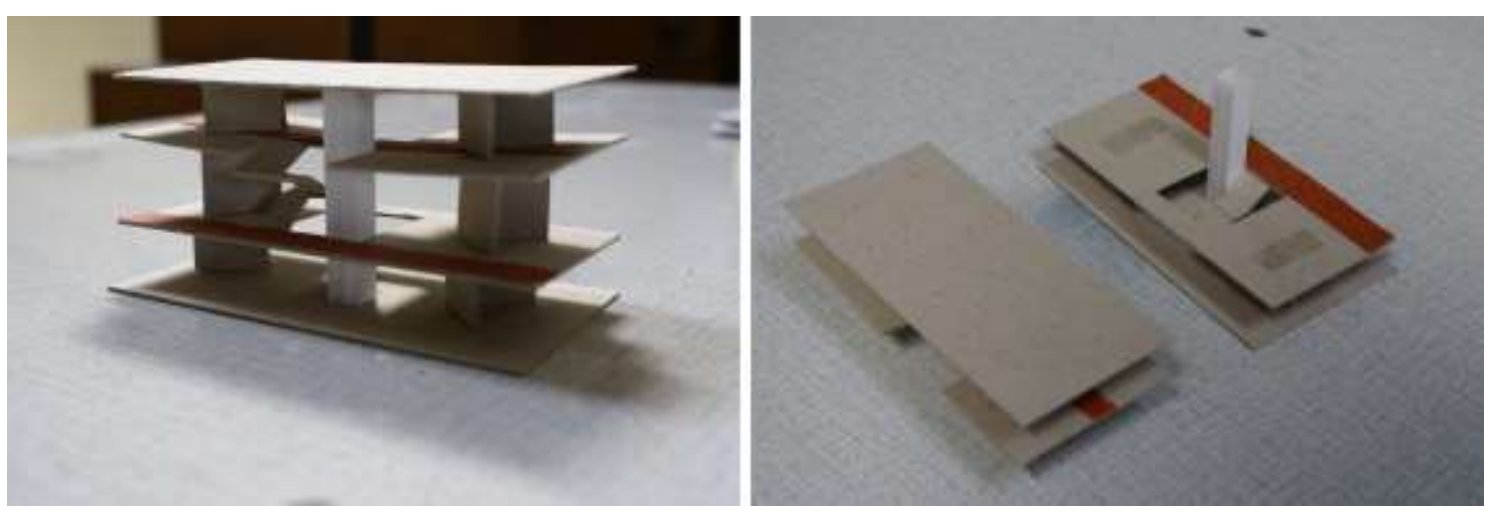

Figure 7. Vignette 4

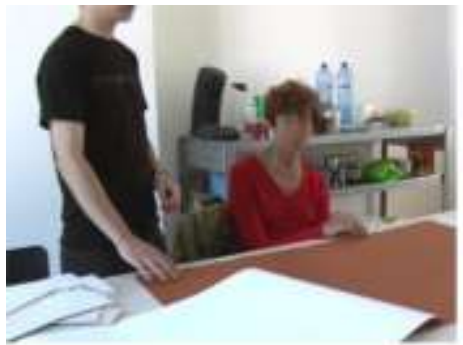

UE2: "eventhing is symbolic, you could alse use sandpaper $[\ldots]$ sindpaper for the road would be good, and this [textured paper] ax grass, but all that is sonvention?

$\mathrm{RA}$ : "convention on the oae hand, intuition on the other:"

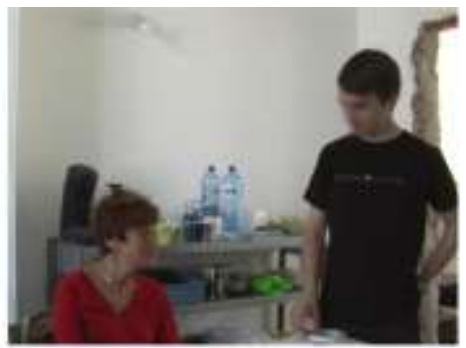

[...]

UE2; "you can do a lot with wall paper, it has a for of texture, and there are many different kinds."

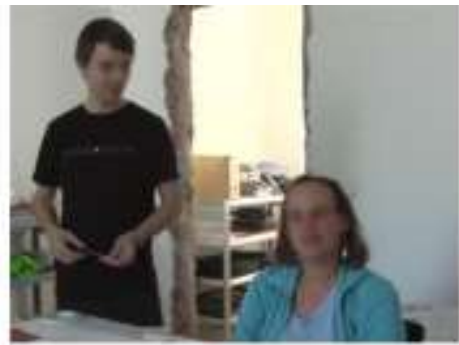

UEl: "you should get a sample book for wall papers, there are many cool [testures], you could cover a model with it so you know "this gives that feeling", a rough façade, a smooth façade. [...] So if you suoch, you could almost figure it out by yourself. 
Figure 8. Vignette 5

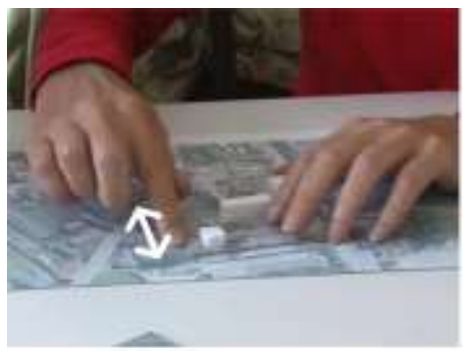

UE2: "and the people would then enter where?'

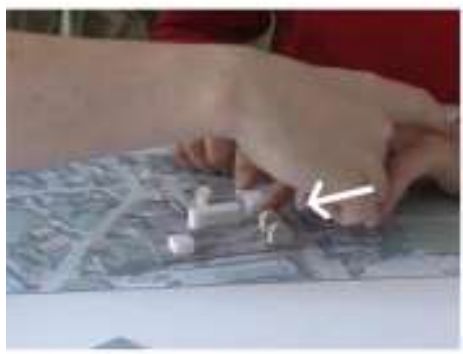

RA takes UE2's finger and moves it] RA: the intention is to, in the location of your index finger, the entrance, to enter the site'

Figure 9. Vignette 6

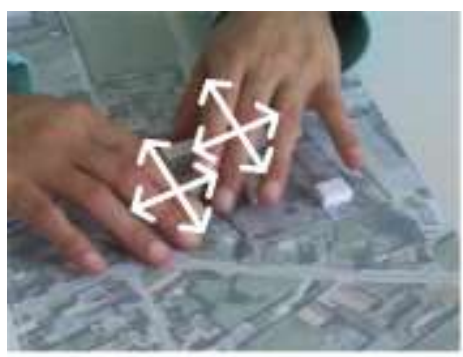

UE1 explores the model with her hands extensively]

Figure 10. Vignette 7

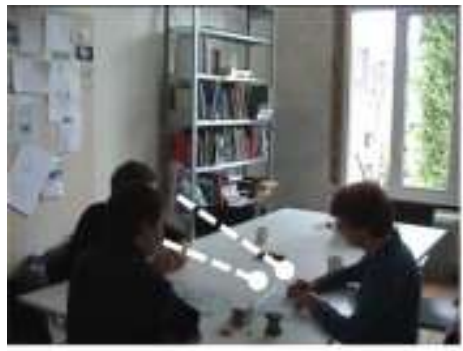

A: 'So now you hase those two existing houses UE2: 'Yes, the town hall'

A: 'And those are two new'

[UE2 touches two specific volumes in the model]

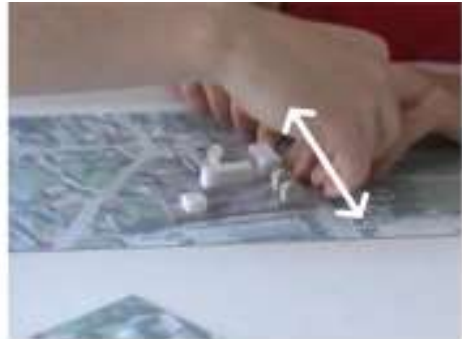

RA: "you can enter the xite from this side too" [RA takes UE2's finger and slides is alongside the front side border

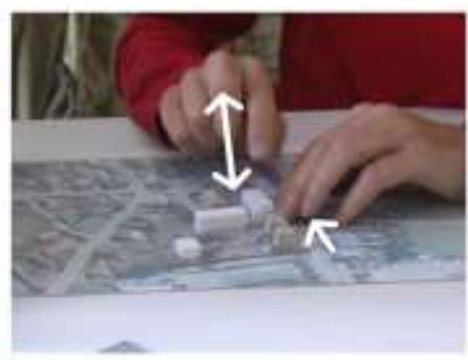

$\mathrm{R}$ - 'while now'

RA: 'while now the site is entered here, to the right, where now the parking is'

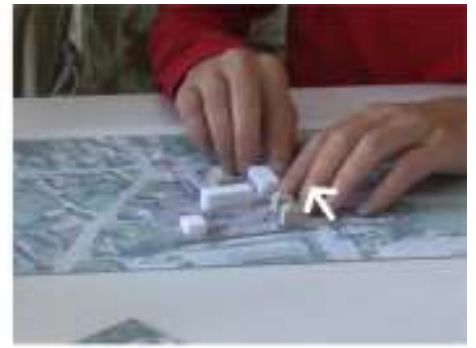

RA: 'you can circulate between thoxe houses" [UL2 2 maves her finger between the volumes of the two remaining houses]

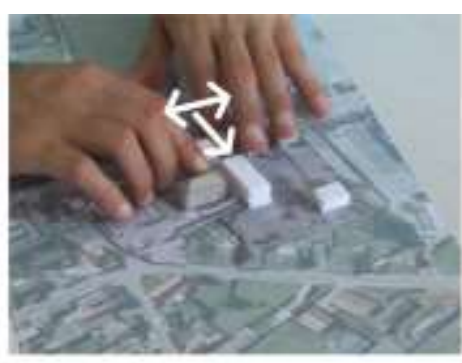

UE1: "and where would the entrance be, here? IUEI has her finger in the spot that was

previously described as the entrance to the site]

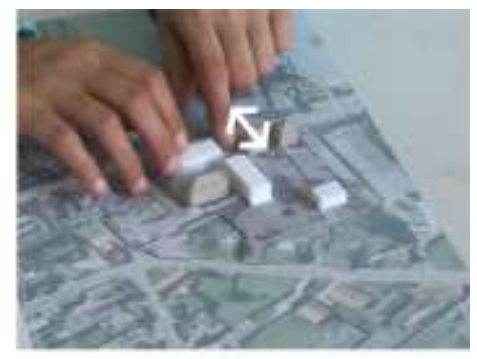

RA: 'there yes, at your index finger UE1: 'between those

[UE] touches the sides of wolumes] RA: ' where there comes an enclosed space'

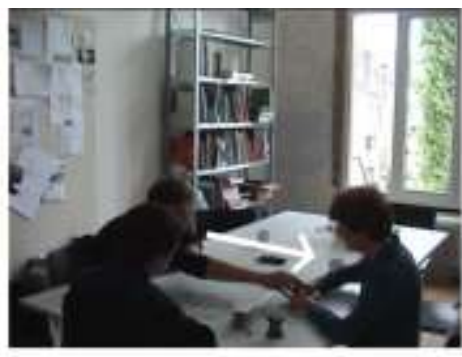

A: and the fromt volume, this volume [A takes UE2's finger and repositions in]. is also a bew wolume that stands in front of the current town hall ... and because of that, we get actually, here we get already some of the ganden

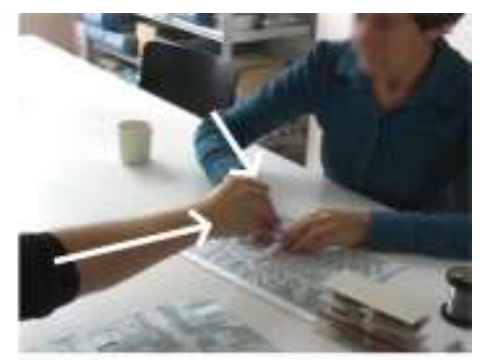

A: tbot mainly here in the middle, if you [UE2 moves finger towands the general diretion of the eentral space between the wolumes and $\mathrm{A}$ takes her hund to position her finger more precisely] yes, this space will also foel as being part of the park. 
Figure 11. Vignette 8

Context discussion about distances between wervices in the building.

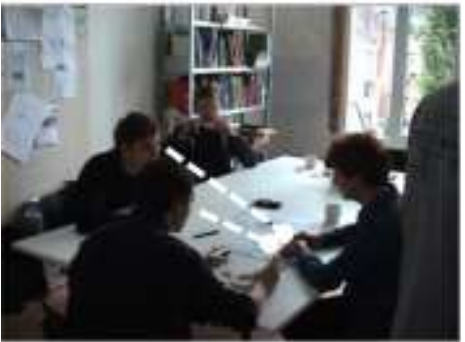

UE2 puts each index finger at a cotner in the model along the length of one building wing. RA and $A$ look at her hands?

UE2: 'Yes, and what are llow dimensions again'? So this is 10 maters?

RA: ' 27 meters'

UE2: ' 27 meters

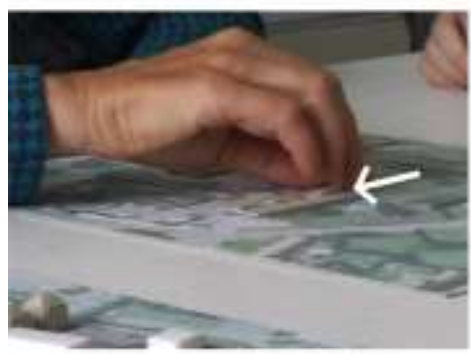

UE2 pinches the other bridge and sbides her thamb and index linger alung the length of the bridge]

UE2: Yes and that'

A: 'That as well"

Figure 12. Vignette 9

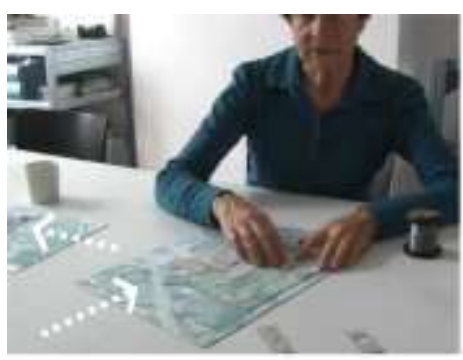

RA: ' I will, maybe first the model of 1/500 of last week, $\Gamma^{\prime}$ lave adapted if a linte, and detailed [RA takes away ooe model and places inother at UE:2's fingertips; UE2 starts foeling different parts of the model]

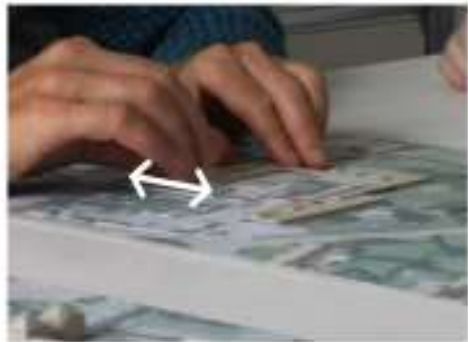

[UE2 maves ber right index finger along the width of the wing]

RA: 'And 13 ineters wide"

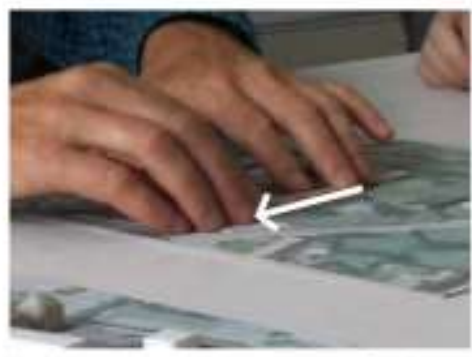

[UE2 puts left index finger on comer of anothet building wing and stides tight index finger along its edge]

UE2: 'Ah yes, yex and this is a loager building' A: 'And this is a longer building'

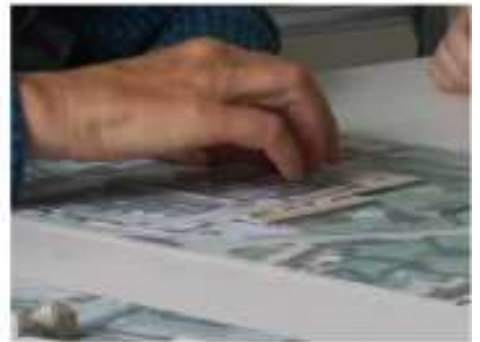

[UE2 pinches wish right thumb and index finger the bridge betwoen two wings]

UE2: 'So this is loteg too he

RA: "That's 10 meters"

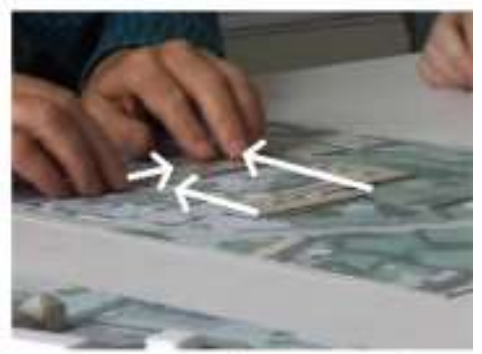

[UE2 moves both index fingers in a paralle! direction towards the edge of the first building wing until her left finger matches a corner, and then moves her right index finger perpendicular towands the otber comer, shortening the distance between both fingers]

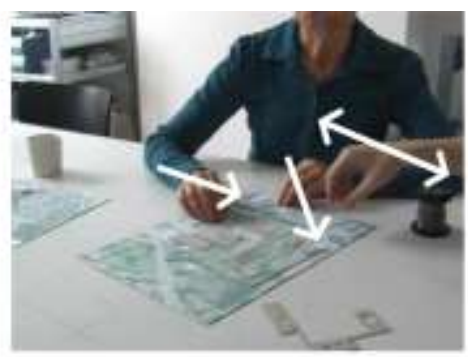

[UE2 is explocing tho model: RA hesitates] RA: 'So I'll first..

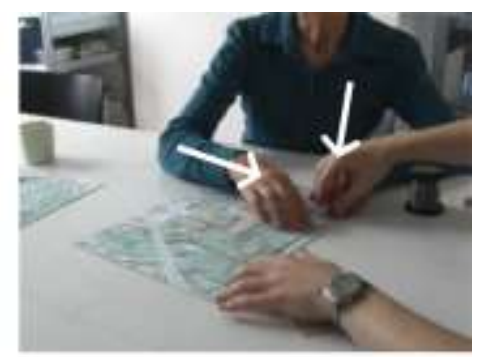

[RA eently tooches one hand of UE2: UE2 puts her nghts index finger in the place; RA moves ber finger along ono of the ediges] RA: ... let you feel ... euh yes, so euh, this is actually the street side' 